DOI 10.37882/2223-2982.2021.01.20

\title{
ПЕДАГОГИЧЕСКИЙ ИНСТРУМЕНТАРИЙ ПРОТИВОДЕЙСТВИЯ ВЛИЯНИЮ ИДЕОЛОГИИ ЭКСТРЕМИЗМА НА ВОЕННОСЛУЖАЩИХ
}

\section{PEDAGOGICAL TOOLS FOR COUNTERING THE INFLUENCE OF EXTREMIST IDEOLOGY ON MILITARY PERSONNEL \\ S. Merkulov \\ Ye. Turkin}

Summary: The authors analyze the methods of manipulative influence of leaders (ideologists) of extremist organizations on the minds of young people. Attention is focused on the informational aspect of involving young people in the ranks of extremist organizations, and the ways through which the influence of the ideology of extremism on military personnel is revealed. The scientific novelty of the article lies in the disclosure of pedagogical tools for countering the influence of the ideology of extremism on military personnel and young people in General. As a result, the ways to improve the measures taken to prevent the influence of the ideology of extremism in the youth environment and in military collectives are identified.

Keywords: pedagogical impact, pedagogical tools, the process of training and education, extremism, ideology of extremism, countering the ideology of extremism.
Меркулов Сергей Владимирович

Адъюнкт, ФГКОУ ВО «Новосибирский военный институт имени генерала армии И.К. Яковлева войск национальной гвардии Российской Федерачии», Новосибирск

sergeyivanoff2015@yandex.ru

Туркин Егор Владимирович

К.п.н., дочент, ФГКОУ ВО «Новосибирский военный институт имени генерала армии И.К. Яковлева войск начиональной гвардии Российской Федерачии», Новосибирск egor-turkin@yandex.ru

Аннотация: Авторами в статье проведен анализ методов манипулятивного влияния лидеров (идеологов) экстремистских организаций на сознание молодых людей. Акцентировано внимание на информационном аспекте вовлечения молодежи в ряды экстремистских организаций, раскрыты пути, через которые происходит влияние идеологии экстремизма на военнослужащих. Научная новизна статьи заключается в раскрытии педагогического инструментария по противодействию влиянию идеологии экстремизма на военнослужащих и молодежь в целом. В результате определены пути совершенствования проводимых мероприятий по превентивной профилактике влияния идеологии экстремизма в молодежной среде и в воинских коллективах.

Ключевые слова: педагогическое воздействие, педагогический инструментарий, процесс обучения и воспитания, экстремизм, идеология экстремизма, противодействие идеологии экстремизма.

\section{Введение}

$\mathrm{C}$ каждым годом в мире возрастает роль глобальной информатизации общества, государства выходят на новый уровень развития информационных технологий, совершенствуются различные направления социальной жизни людей.

Последнее время мы практически не наблюдаем в средствах массовой информации захватов учреждений, самолетов, мощных подрывов бомб и иных ярких проявлений экстремизма и терроризма. Имеют место отдельные случаи, которые несомненно приносят вред обществу и конституционному строю любой страны. Примечательно то, что результатом спокойной жизни граждан, является успешная деятельность силовых структур и организаций по ликвидации экстремистских и террористических организаций, а также их последователей. Возможно, экстремизм приобрел иную форму проявления, распространения и воздействия на слои общества, проникновения в сознание личности через информационные ресурсы и другие средства пропаганды. Присутствие в социальных сетях контента с образцами агрессивного поведения, ложным представлением о вседозволенности, пользуется спросом в молодежной среде. Выбор темы статьи довольно актуален на сегодняшний день, так как молодежь остается в ряде случаев незащищена по отношению к такой мощной силе, как влияние идеологов экстремизма. Как показывает практика воздействию экстремистской идеологии подвергается молодежь, у которой не сформировано мировоззрение и личностная позиция, они находятся в выборе своего будущего, поэтому воздействовать на ее сознание легко. Применяя особые методы и приемы вербовки, лидеры экстремистских организаций легко находят подход к молодым людям, мотивируя их на быстрое разрешение существующих проблем. В исключительных случаях юноши (а порой даже и девушки) выбирают свой жизненный путь через прохождение военной службы по контракту в различных родах войск или офицерскую карьеру. Возникает необходимость понимания порядка проникновения идеологии экстремизма в воинские 
коллективы и поиск педагогического инструментария противодействия этому.

\section{Шель исследования}

Цель исследования заключается в анализе методов манипулятивного влияния идеологов экстремизма на сознание молодежи и поиске педагогического инструментария противодействия такому явлению.

На основе поставленной цели, в исследовании решаются следующие задачи:

- осуществление анализа методов манипулятивного влияния идеологов экстремизма на сознание молодежи и общество в целом;

- раскрытие педагогического инструментария по противодействию влиянию идеологии экстремизма на молодежную среду и воинские коллективы.

\section{Материал и методы исследования}

В качестве метода исследования избран анализ имеющихся положений и выводов, содержащихся в исследованиях отечественных и зарубежных ученых по проблеме распространения идеологии экстремизма в молодежной среде. Теоретической базой исследования послужили работы, раскрывающие средства профилактики и противодействия экстремизму в молодежной среде Н.Б. Бааль [1], А.С. Доколина [5], Ю.Н. Зеленова [6], О.Т. Корнеевой в соавт. [7], А.В. Кузьмина [8], С.В. Расторгуева [14], в воинских коллективах А.Ю. Гузенко [3], Н.В. Максимова [9], труды отечественных и зарубежных ученых О.М. Гусейнова [4], D. Pipes [20], V. Flores [21] о распространении идеологии экстремизма.

Практическая значимость исследования заключается В применении предложенного педагогического инструментария противодействия влиянию идеологии экстремизма среди военнослужащих.

\section{Результаты исследования и их обсужление}

Конец XX и начало XXI столетий ознаменовался всплеском экстремистских проявлений по всему миру. Основанием к этому послужило повышение социальной неопределенности, укоренение негативно окрашенных социально-психологических и эмоциональных состояний людей, что отражалось на характере отношений между представителями разных социальных групп. Низкая оценка уровня ожиданий, уверенности, безопасности и, напротив, высокая - уровня тревоги и страха, отсутствие целенаправленного регулирования этих процессов приобрели антиобщественную активность. Воспользовавшись ситуацией, экстремистские группировки стали активно претворять задуманные цели в жизнь [4]. Ярким примером могут послужить скоординированные террористические акты 11 сентября 2001 года. Для реализации таких крупномасштабных мероприятий экстремистским организациям необходимо иметь огромное количество сторонников.

В целях вовлечения в свои ряды идеологами экстремизма используются определенные методы влияния на человека. Понятие «влияние» неразрывно связанно с понятием «воздействие». В «Словаре русского языка» С.И. Ожегова дается следующее определение понятия «воздействие»: «Действие, направленное на кого(что-) нибудь с целью добиться чего-нибудь, внушить что-нибудь» [10, с 348]. Доктор педагогических наук В.Ю. Питюков в своей работе предлагает интерпретировать «педагогическое воздействие» как «вид деятельности педагога, цель которой - достижение позитивных изменений психологических характеристик воспитанника (потребностей, установок, отношений, состояний, моделей поведения)» [11, с. 107]. Поэтому, ориентируясь на несостоятельность государства, идеологи экстремизма, завлекая население (особенно молодежь) перспективами успешной жизни, осуществляли обучение явных активистов (для выступлений и полемики), помогали в организации разного рода торжеств, спонсировали свадебные церемонии, которые не по карману молодоженам. Молодое поколение чувствовало заботу, появлялась привязанность к новому сообществу. В сознании и чувствах общества появлялась мысль, что можно обойтись и без государства. Молодые люди выступали в роли воспитанников, а лидеры экстремистских группировок становились для них учителями, обладая с виду всеми необходимыми качествами: авторитетом, оптимизмом, уважением к своим воспитанникам, вниканием в их нужды. Понимая душевное состояние человека, идеологи без всяких проблем осуществляли навязывание ему необходимую оценку действительности, применяя следующие методы: убеждение, внушение доверием, манипуляцию, побуждение к подражанию на фоне личных успехов, а в отдельных случаях, даже принуждение.

В 2017 году Игнасио В. Флорес - декан Факультета общественной безопасности колледжа Рио Хонда в Калифорнии, опубликовал труд под названием «Педагогика насильственного экстремизма», в котором провел исследование по критическому анализу проявлений экстремизма через призму педагогического развития. Ученый в своем исследовании, применяя междисциплинарный подход, в исследовании раскрывает положения о том, как идеологи экстремизма учат людей ненавидеть друг друга, и в результате решительно действовать, используя насилие [21]. В Англии при захвате людей, причастных к деятельности экстремистских группировок, в помещениях были обнаружены учебные пособия, содержащие целый курс обучения о том, как стать террористом. После перевода текстов выяснилось, что путем обмана молодой человек, как внедренный агент, должен 
был устроиться в организацию (или пойти на службу в армию) для получения первоначальной военной подготовки, а после увольнения, прибыть к месту расположения группировки для обучения других [20].

Так было ранее. В современном мире, где общество стремительно развивается, изменяются методы вовлечения молодежи к противозаконной деятельности, применяемой экстремистами. Учебные пособия ушли в прошлое, теперь воздействие идеологов экстремизма, на молодых людей, происходит через социальные сети и Интернет. Методология, используемая в распространении идеологии экстремизма, подобна уличному продавцу, торгующему сомнительной смесью продуктов для прохожих, где процесс обнаружения «некачественного продукта» зависит только от покупателя. Молодежь жаждет открытий, поэтому сеть «Интернет» для них свобода действий для познания нового и неизведанного. Анонимность виртуального пространства позволяет идеологам экстремизма размещать необходимый контент для вовлечения в свои ряды в свободном доступе, прикрываясь вполне легитимными названиями сайтов и аккуантов. Имеются яркие примеры успешной вербовки юношей и девушек через социальные сети в состав группировок экстремистов. Так в сентябре нынешнего года сотрудниками Федеральной службы безопасности, совместно с Росгвардией осуществлено задержание 13 человек, подозреваемых в подготовке насильственных действий в школах и других общественных местах с использованием самодельных бомб, зажигательных смесей и холодного оружия в разных регионах страны. Большая часть задержанных состояла в закрытом сообществе «Вконтакте», где и обменивалась идеями о будущих планах [2]. Существуют разные механизмы обработки пользователей в социальных сетях. Рассмотрим один из наиболее применяемых идеологами экстремизма, состоящий из двух этапов:

1. 1 этап - идеологическое давление. Данный этап представляет собой создание и распространение искаженных представлений о современном обществе, о роли радикальных течений, их сущности под видом «исправления» собственных жизненных ошибок.

2. 2 этап - психологическое воздействие. Этап необходим для индивидуального воздействия на личность, посредством манипулирования. Для этого используются методы: делай как все (пример многотысячного количества подписчиков), делай для себя (пример улучшения социальных условий жизни человека), приводя примеры внушительного количества подписчиков.

Любой человек, имеющий доступ к Интернету, может подключаться к различным сайтам, в том числе и экстремистской направленности. Такой доступ индивидуален и обезличен. Пользователь находит тех, с кем можно поделиться знаниями, задать вопрос об интересующей его теме. В этом ключе он может попасть в поле внимания вербовщиков, обладающих знанием механизма вовлечения в ряды группировок. Кроме представленного механизма выше, имеют место и традиционные методы пропаганды, в том числе использование проповедей в религиозных заведениях или при посещении так называемых «кружков» по интересам, индивидуального коммуникативного воздействия в учебных заведениях, по месту работы или досуга, передача листовок. Поэтому необходимо актуализировать педагогический инструментарий, который поспособствует противодействию влиянию идеологии экстремизма.

Понятие педагогического инструментария используют многие отечественные и зарубежные ученые. В своей статье доктор педагогических наук Е.Н. Стрельчук, проведя анализ подходов к толкованию понятия «педагогический инструментарий», предлагает его авторское определение и раскрывает значимые компоненты в процессе обучения и воспитания. Так основными компонентами педагогического инструментария будут являться: подходы, принципы, формы, методы, средства, технологии, приемы обучения и воспитания. Раскроем некоторые средства противодействия влиянию идеологии экстремизма. Они будут содержать несколько уровней: государственный, общественный, личностный [15].

Государственный уровень регулирует нормативными актами деятельность сайтов по распространению информации в сети и своевременную публикацию материалов, признанных в стране экстремистскими материалами. Например, за 2018 год «в социальной сети «Вконтакте» было удалено более 7,9 млн. единиц контента, связанного с поощрением самоубийств или нанесения увечий, заблокировано свыше 1,8 млн. уникальных профилей и 11,3 тыс. сообществ, через которые такие материалы распространялись» [14, с. 124-145]. Государство, осознавая остроту проблемы влияния на молодежь идеологии экстремизма, утвердило ряд распоряжений Правительства Российской Федерации: «Основы государственной молодежной политики Российской Федерации на период до 2025 года» [13] и «Стратегия развития воспитания в Российской Федерации на период до 2025 года» [12]. В указанных документах определены задачи и направления деятельности государственных, общественных органов, образовательных организаций по воспитанию молодежи в системе духовно-нравственных ценностей. Кроме того, в Федеральном законе «Об образовании в Российской Федерации» закреплено положение о том, что в ходе образовательной деятельности запрещены политическая агитация, а также принуждение к принятию политических, религиозных или иных убеждений [19]. В соответствии со «Стратегией противодействия экстремизму в РФ до 2025 года» [16] в качестве субъектов противодействия экстремизму рассматрива- 
ются не только органы государственной власти разного уровня, органы местного самоуправления, институты гражданского общества, но и организации (общественный уровень) и физические лица (личностный уровень).

Общественный уровень включает повышение уровня авторитета церкви, семьи, морали и совести, недопущение применения грубости и насилия, пропаганду ценностей, толерантности, законности и социальной справедливости. Средства массовой информации, социальные сети и Интернет непосредственно будут оказывать помощь в совершенствовании политики гражданско-патриотического и духовно-нравственного воспитания молодежи. Представляя собой управляющую среду, обеспечивая социально экономическую, политическую и духовную жизнь общества, социальные сети и Интернет должны содержать контент, позволяющий открывать и формировать не отдельные элементы нравственности, а систему нравственных ценностей, основанную на духовной и культурной традиции народа, предупреждающую религиозную безграмотность, историческую недостоверность и нигилистическое отношение к собственному прошлому. Средства массовой информации будут способствовать формированию у молодежи информационного контента гражданственности, интернационализма, толерантности к другим культурам, организовывать работу различных площадок для обсуждения актуальных проблем, применяя технологии дискурсивного управления. На этом обращает внимание в своей работе Ю.Н. Зеленов констатируя, что эффективным средством предупреждения (профилактики) вовлечения молодежи в ряды экстремистских организаций будет являться взаимодействие органов внутренних дел и средств массовой информации в следующих направлениях:

- «периодические публикации положительных примеров результативного противодействия преступлениям экстремистской направленности среди несовершеннолетних;

- выступления с разъяснением действующего законодательства о порядке наступления уголовной ответственности за совершение преступлений экстремистской направленности;

- информационные сообщения в радиоэфире, демонстрация видеосюжетов на телевидении, публикация в прессе материалов, направленных на разоблачение лиц, причастных к экстремистской деятельности, и раскрытие истинных целей экстремистских организаций;

- привлечение журналистов к освещению мероприятий воспитательного характера, в том числе спортивных и направленных на патриотическое воспитание» [6, с. 84].

Личностный уровень заключается в формировании у молодых людей готовности к противодействию манипулятивному внешнему воздействию. Примером фор- мирования готовности и применения методов и средств обучения и воспитания необходимых для этого в свое работе описывает А.С. Доколин. Ими являются методы: демонстрация, рефлексия, игра, упражнение, объяснение; средства: электронные, аудиовизуальные, технические, информационные, диагностические [5]. Уверенное поведение молодого человека при работе с информацией, в споре, дискуссии, грамотное отстаивание собственной точки зрения, выступают показателем его высокой морально-психологической устойчивости. А.В. Кузьмин предлагает использовать в профилактике экстремистского поведения молодежи воспитательный потенциал досуга, наполняя его социально-культурным содержанием [8].

Казалось бы, что на военной службе, все строго регламентировано, но информатизация распространяется и в воинских частях. Обычные телефоны сменяют «умные» смартфоны, обладая множеством функций. Рассмотрим, как вышеуказанные уровни способствуют противодействию влияния идеологии экстремизма на воинские коллективы. На государственном уровне внесены изменения в Федеральные законы от 27 мая 1998 г. № 76-Ф3 «О статусе военнослужащих» и от 28 марта 1998 г. № 53-Ф3 «О воинской обязанности и военной службе». Так отдельным пунктом закон гласит о запрете военнослужащим с использованием информационно-телекоммуникационной сети «Интернет распространять данные, позволяющие определить принадлежность или предназначение военнослужащих, в том числе информацию, позволяющую определить место нахождения военнослужащих в определенный период другими лицами» [18]. Запрет также касается распространения информации о своей деятельности или деятельности других военнослужащих и органов военного управления, связанной с исполнением обязанностей военной службы. В целях реализации указанного пункта прописано, что военнослужащим запрещено «использовать и иметь при себе при исполнении обязанностей военной службы электронные изделия (приборы, технические средства) бытового назначения, в которых могут храниться или которые позволяют с использованием информационно-телекоммуникационной сети «Интернет» распространять или предоставлять аудио-, фото-, видеоматериалы и данные геолокации» [19].

Примером реализации средств противодействия на общественном уровне может послужить запуск с 1 октября 2020 года Федеральной службой войск национальной гвардии Российской Федерации уникального познавательного медиапроект «Проверка на прочность». Проект имеет предназначение наглядного знакомства молодежной аудитории страны со спецификой служебной деятельности подразделений вновь созданной силовой структуры. В нем участвуют российские звёзды кино, телевидения, эстрады и блогосферы, которые 
опробуют себя в роли военнослужащих и сотрудников различных специальностей, выполняя соответствующие задания под руководством профессионалов. Видеоролики «Проверки на прочность» размещаются на официальном YouTube-канале ведомства. Такой формат контента очень привлекателен для молодежи, кроме того, он показывает, насколько опасно выполнение задач войсками, в том числе по борьбе с экстремизмом и терроризмом. Каждое силовое ведомство страны активно ведет пропаганду противодействия экстремизму и другим негативным явлениям современности в социальных сетях. Помимо официальных страниц в сети «Интернет» у силовиков имеется контент в «Вконтакте», «Одноклассники» и других социальных ресурсах. На указанных страницах пользователь может получить доступ к необходимой информации по вкладке «противодействие экстремизму». Статистика запросов сайтов по данным Google Trends показывает, что больше всего (около 60\%) пользователи обращаются к учебным и видеоматериалам, остальные запросы касаются данных по нормативной базе и перечням организаций и материалов, признанных в стране экстремистскими.

Процесс обучения и воспитания военнослужащих сложен и многогранен. Он меняется в зависимости от условий складывающейся обстановки, возрастанию требований к военнослужащему, как специалисту. Изучая труды А.Ю. Гузенко, Н.В. Максимова исследователями предлагается применять совокупность традиционных, активных, интерактивных методов обучения и воспитания, которые позволят сформировать необходимые качества у военнослужащих, способствующие противодействию влияния идеологии экстремизма и иных негативных явлений. А.Ю. Гузенко - это умение критически оценивать информацию [3], а у Н.В. Максимова - ценностное отношение к противодействию экстремизму [9]. Способность молодого человека, проходящего военную службу по контракту, в служебнобоевой деятельности не только противостоять чужому влиянию, но и оказать встречное воздействие возможно на основе развития личностного уровня в процессе обучения и воспитания, является показателем наивысшей степени сформированности у военнослужащего гражданственности, патриотизма и духовно-нравственных ценностей.

\section{Зак^ючение}

Таким образом, подводя итог вышесказанному, можно сделать следующие выводы:

- распространение и тиражирование информации имеет цепную реакцию, что позволяет охватывать несколько аудиторий одновременно, создавая эффект синергии и способствуя дальнейшему вирусному распространению экстремистской идеологии;

- от размещения положительного контента, направленного на противодействие идеологии экстремизма в социальных сетях и на сайтах сети «Интернет» зависит уровень антиэкстремистской работы с молодежью;

- от государственных органов зависит своевременный анализ формата, стилистики и контекста публикаций, мониторинг позитивной и негативной информации по экстремистской и антиэкстремистской тематике, оперативного реагирования и выбора максимально эффективных форм противодействия;

- от образовательных и общественных организаций при проведении общественно-политических, культурных, спортивных и других мероприятий, направленных на противодействие экстремизму, зависит уровень положительного отношения молодежи к духовно-нравственным ценностям общества.

Результатом перечисленных мероприятий станет формирование отторжения абсолютным большинством молодого поколения даже самой мысли о применении насильственных методов для разрешения каких-либо конфликтов и противоречий.

Направлением дальнейшего исследования может послужит проведение анализа основных подходов и принципов противодействия влиянию идеологии экстремизма в молодежной среде и воинских коллективах.

\section{ЛИТЕРАТУРА}

1. Бааль Н.Б. Методы профилактики политического экстремизма молодежи // Вестник Нижегородского университета им. Н. И. Лобачевского. Нижний Новгород, 2012. № 1 (1). С. 293-297.

2. В Воде спецоперации ФСБ задержаны 13 человек в ряде регионов Российской Федерации [Электронный ресурc]. URL: https://www.1tv.ru/news/2020-09-04/ (дата обращения: 07.09.2020).

3. Гузенко А.Ю. Педагогические условия формирования умения критически оценивать информацию в сети Интернет у курсантов военных институтов войск национальной гвардии Российской Федерации: автореф. дис. ... канд. пед. наук. Санкт-Петербург, 2020. 27 с.

4. Гусейнов 0.М. Экстремизм и терроризм как антиподы общественной и личной морали // Исламоведение. 2015. № 4. С. $36-42$.

5. Доколин А.С. Формирование готовности студентов вуза к противодействию вовлечению в киберэкстремистскую деятельность: автореф. дис. .... канд. пед. наук. Белгород, 2017. 24 с. 
6. Зеленов Ю.Н. Молодежный экстремизм: феноменология, история, проблемы профилактики: учебное пособие / Ю. Н. Зеленов. - Москва: Изд-во ФГКУ «ВНИИ МВД России», 2014. -151 с.

7. Корнеева 0.Т., Самыгин С.И., Кротов Д.В. Молодежный экстремизм как угроза национальной безопасности общества: Причины распространения и меры противодействия // Гуманитарные, социально-экономические и общественные науки. Краснодар, 2016. № 10. С. 76-80.

8. Кузьмин А.В. Социально-культурная профилактика экстремизма в молодежной среде: автореф. дис. ... док. пед. наук / А.В. Кузьмин. - Тамбов, 2015. 41 с.

9. Максимов Н.В. Формирование ценностного отношения к противодействию экстремизму у курсантов ВУЗов войск национальной гвардии Российской Федерации: автореф. дис. ... канд. пед. наук. Челябинск, 2019. 27 с.

10. Ожегов С.И. Словарь русского языка. 17-е изд., стереотип. М.: Русский язык, 1985.

11. Питюков В.Ю. Основы педагогической технологии: Учеб.-методическое пособие: М., 2001. 188 с.

12. Распоряжение Правительства РФ от 29 мая 2015 г. № 996-р «06 утверждении Стратегии развития воспитания в Российской Федерации на период до 2025 года» [Электронный ресурc]. URL: http://www.consultant.ru/ (дата обращения: 07.09.2020).

13. Распоряжение Правительства РФ от 29 ноября 2014 г. № 2403-р «0б утверждении Основ государственной молодежной политики РФ на период до 2025 года» [Электронный ресурc]. URL: http://www.consultant.ru/ (дата обращения: 07.09.2020).

14. Расторгуев С.В. Экстремизм в молодежной среде современной России: виды, факторы распространения, мягкие технологии профилактики // Политическая наука. 2018. № 4. С. 124-145.

15. Стрельчук Е.Н. Педагогический инструментарий: сущность, употребление и роль понятия в российской и зарубежной педагогике // Перспективы науки и образования. 2019. № 1 (37). С 10-19.

16. Указ Президента Российской Федерации от 29 мая 2020 г. № 344 «06 утверждении Стратегии противодействия экстремисткой деятельности до 2025 года» [Электронный ресурc]. URL: http://www. https://www.garant.ru/products/ipo/prime/doc/74094369/ (дата обращения: 07.09.2020).

17. Федеральный закон от 27 мая 1998 г. № 76-Ф3 «0 статусе военнослужащих» [Электронный ресурс]. URL: http://www.consultant.ru/ (дата обращения: 15.11.2020).

18. Федеральный закон от 28 марта 1998 г. № 53-Ф3 «0 воинской обязанности и военной службе» [Электронный ресурс]. URL: http://www.consultant.ru/ (дата обращения: 15.11.2020).

19. Федеральный закон от 29 декабря 2012 г. № 273-Ф3 «06 образовании в Российской Федерации» [Электронный ресурс]. URL: http://www.consultant.ru/ (дата обращения: 10.11.2020).

20. Pipes D., Nafisi A. Is Islamism Dead? The Future Islamism in the Muslim World. Policywatch. Washington Institute for Near East Policy. 1999. Suite 1050 [Электронный pecypc]. URL: http://www.danielpipes.org/article/304 (дата 0бращения: 07.09.2020).

21. Flores V. The pedagogy of violent extremism. Description. New York: Peter Lang. 2017. 188 p.

๑ Меркулов Сергей Владимирович (sergeyivanoff2015@yandex.ru), Туркин Егор Владимирович (egor-turkin@yandex.ru).

Журнал «Современная наука: актуальные проблемы теории и практики» 